\title{
The Development of the Socket Type EPS Plate Cutting Equipment Hongyu Guo ${ }^{1, ~ a, ~ H e ~ G o n g ~}{ }^{2, b,{ }^{*}}$, Bin Liü,c
}

${ }^{1}$ Engineering \&Technology College, Jilin Agriculture University, Changchun 130118, China

${ }^{2}$ Information \&Technology College, Jilin Agriculture University, Changchun 130118, China

${ }^{*}$ Corresponding author

Keywords: EPS plank, Socket type cutting, Complex shape cutting

Abstract. Polystyrene foam (EPS), commonly known as benzene board, foam board, is widely used in architectural decoration, road construction, the film set, a lot of fields such as packaging boxes, has a broad market need and the use value.

For EPS plate mainly have three kinds of different processing ways: the first is a manual cutting, the insulation measures by hand-held electric cutting wire cutting plate workers, after cutting the shape and position of the completely determined by the human, the disadvantage is that the machining accuracy cannot be guaranteed, low machining efficiency and has certain security hidden danger; The second is simple cutting machine, there are also on the market at present the modelling of EPS board equipment, mainly a piece of block style cutting equipment, decorative line cutting equipment, modelled on the shape of CNC cutting equipment, etc., the disadvantage is that the equipment can only to the modelling of simple cutting of EPS board, unable to realize intelligent into batch, production line, cutting; Better effect to use socket type EPS plank production mainly adopts the way of injection molding, because of the need to make a special mold, so the cost is very high, the production efficiency is not high, unable to meet a wide range of promotion and use.

EPS plate cutting equipment developed by socket type, (1) implementation for EPS plate surface modelling cutting; (2) accept PC nc instructions, complete electric cutting the numerical control cutting wire cutting speed (location), improve the quality and precision of the cutting incision surface, complete dovetail groove, saw form tank, trapezoidal groove etc all kinds of different shape and size of the slot cutting; European-style building eaves, foot line, the Roman column form, such as cutting; Immobilized and the commonly used form of cutting data, facilitate into batch repeatedly cut production.

\section{Introduction}

Polystyrene foam (EPS), commonly known as benzene board, foam board, have qualitative light, sound insulation, heat insulation, anti-seismic, moistureproof, low coefficient of thermal conductivity, low water absorption and excellent performance[1], is widely used in architectural decoration, road construction, a lot of fields such as movie props, packing box, has a broad market prospect and using value. More widely applied in the construction industry, such as facade and the foundation of thermal insulation, inversion type roof, EPS sandwich color steel plate, steel wire rack sandwich board, building special modelling [2-3], EPS foam products, as shown in Fig. 1.

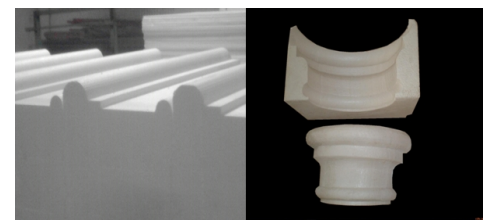

Fig. 1 EPS foam products 
Jilin province is in the northeast old industrial base, in the cold region of China, winter low temperature, the heating cycle is very long, urban residents heating problem is a very important problem of the people's livelihood, and stuck around for years failed to thoroughly solve the problem of Jilin province. At present, in the cities of Jilin province has quite a lot of the energy-saving building, at the same time, the doors and Windows broken, heat preservation performance is poor, urban heating need to consume energy greatly. Government departments for the key problem of the people's livelihood "warm house" project put forward for the reasonable solution [4]. "Warm house" project is mainly aimed at no \&interior wall thermal insulation layer of the house of the old village to paste for EPS board exterior wall thermal insulation surface as a series of projects. The pilot of Jilin province is "warm house" project, is a big demand for EPS panel, but the lack of on the market at present on the cutting of the EPS plate comprehensive and intelligent control system, lead to a lot of construction site using artificial means to cut or use simple equipment to carry on the simple modelling, unable to realize fast, flexible and intelligent cutting. And socket type EPS plate modelling is the injection way more used at present, low cost, high efficiency, large-scale promotion.

Therefore, a socket type EPS plate cutting machine for large-scale promotion of EPS use has very important significance, at the same time the cutting system can also be applied to disappear of die cutting in related fields.

The Main Form of EPS Board. Currently building insulation materials mainly include polystyrene board (hereinafter referred to as the foam plank), extruded polystyrene, rock wool, polystyrene particles, etc., are widely used in recent years mainly can be onset and extruded type. Can send sexual foam insulation board as part of the organic heat preservation material, light weight, stable moist heat insulation; A certain compressive and tensile shear strength; Modelling, easy cutting, easy polishing. Appropriate water vapor permeability, prevent the internal condensation, etc. And extrusion type has better strength and density, but the plate is brittle, not easy to bend, easy condensation, poor permeability materials in recent years to try to use, no relevant standard in our country, Europe and the United States, South Korea and other thermal insulation technology advanced countries there is no use [5].

EPS plate mainly divides into the joining together of straight spell and socket type two kinds of forms, relative to the straight spell type way of joining together, socket type splicing has better robustness and heat preservation effect, socket type plate 3D graphic, as shown in Fig. 2. But because the socket type of modelling is more complex, the current production process mainly adopts EPS plate injection molding processing, EPS plate processing injection molding based on polystyrene as raw materials by the pretest bubble in advance a (foam), drying, curing processing, by EPS plate machine automatically after the pretest bubble bead material into the mold cavity, and then pass into the secondary foam steam heating, heat preservation sinter type, then through the exhaust cooling after setting, by the ejection rod ejection mould will be manufactured goods[6-7], but the production cost is higher, the production efficiency is low, cannot be promoted and widely used in related industries. Can be mass production by means of hot wire cutting socket type of EPS board, solve the problems. But need comprehensive control in the process of cutting material in the feeding speed on the guide rail, electric heating wire cutting speed, electric heating wire electric current size, in order to get the best quality and forming effect of incision. 


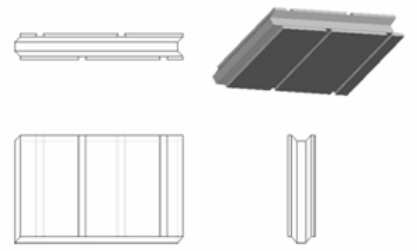

Fig. 2 Socket plate foam three-dimensional map

The Existing Development Situation of Cutting Equipment. (1) foam plank type cutting machine

Block cutting machine structure is simple, single function, low accuracy, only for a horizontal interface block plate cutting.

(2) foam plank adornment line cutting machine

Decorative type line cutting machine cut the main body for building eaves, foot line and dovetail groove of plate type body, as the market is on the adornment of the line cutting machine used for ordinary gantry cutting machine structure, causes the cutting efficiency is lower.

(3) socket type foam plank injection molding equipment

Implements the socket type foam plank production, foam plank four sides all have the socket interface, the plate with a dovetail groove, effectively prevent the building exterior wall thermal insulation layer the metope inside the empty drum, crack, fall off and get damp, cold, condensation of engineering quality common fault, greatly improve the durability of the external thermal insulation layer. But the molding process of the production equipment is expensive, and each plate need to have a separate mould, make the product specifications and flexibility is low, a complete set of production equipment cost up to hundreds of thousands of yuan, even hundreds of millions of yuan, production out of the socket type plate prices high, large scale promotion.

\section{EPS Plate Cutting Equipment Mechanical Structure}

Cutting Equipment Mechanical Scheme. Scheme 1: using hydraulic control spindle, three axis gantry and horizontal planer mechanical movement.

Scheme 2: use of stepper motor coupling, drive the ball screw rotation, the control of the main shaft, three axis gantry and horizontal planer mechanical movement.

In scheme 1 hydraulic pressure due to the transmission power is big, easy to transfer and the configuration, control is higher, the slider bearing larger, running more stable with high feasibility. But because is suitable for the hydraulic system of the model accuracy requirement is too small and because of its cost is too high, in a simulated experimental prototype is not applicable. So as to improve easily in screw will have excessive deflection, because the weight of simulation prototype body design based on 1:10 is small, so the simulation phase, the second scheme using screw can be used to control the mechanical movement device, and screw compared with hydraulic cost is lower, is suitable for this equipment research and development. The whole $3 \mathrm{~d}$ drawings as shown in Fig. 3.

Main realization socket type complex modelling method based on micro controller and step motor as the main part and mechanical transmission parts. With microcontroller as the main chip, controlled by step motor spindle, drives the ball screw mechanical movement, realize the foam plank three-dimensional socket type cutting and cutting shape. Cutting foam plank with a socket interface module is assembly line features, the main technical points is to first use of ball screw transmission drive electric cutting wire cutting slot plug and then by the ball screw mechanical 
transmission to dovetail groove type plate cutting, plate of raw materials before cutting socket interface is a piece is not separated as a whole, so the material position will not change, can precisely control the cutting position of the socket interface to ensure that the stitching, conforms to the standard, and realizes the high efficiency work.

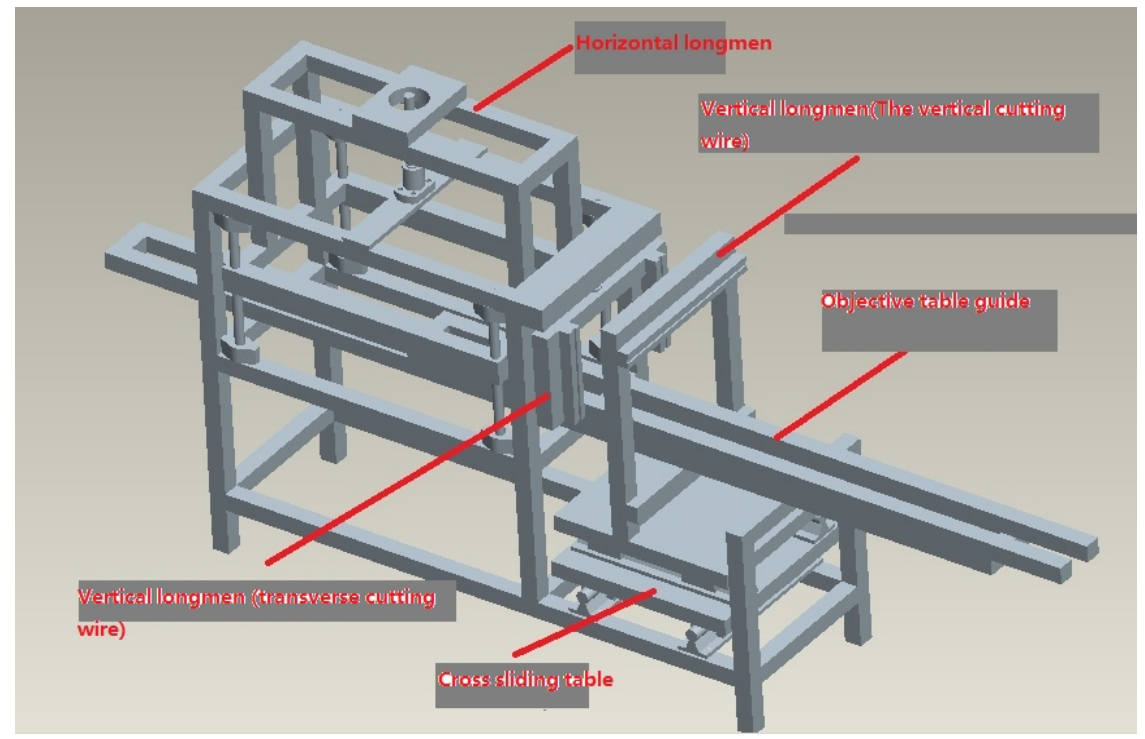

Fig. 3 The Map of the Three-Dimensional

Three Dimensional Cutting Socket Type Interface. Use of mechanical structure combined with single-chip set of ball screw trajectory, really realize the three dimensional socket cutting and cutting shape. $3 \mathrm{~d}$ foam cutting machine combined with three-axis linkage gantry cutting device with horizontal cutting device respective advantages, experimental verification of gantry frame using performance and the stability of block cutting, provide further theoretical basis for biaxial cutting planer design[8]. Adopt stepper motor drives the ball screw precision control and sectional mode, whole cutting (mainly for $3 \mathrm{~d}$ sheet metal cutting) and fission cutting (mainly for certain adornment line cutting).

Cutting process in two steps to complete the work. The first step, the use of ball screw drive cutting block foam plank, get four sides have continuous socket interface board, as shown in Fig. 4 . The second step, again using the ball screw drive to dovetail groove cutting of sheet, precise bulk cut out three dimensional socket type foam plank, as shown in Fig. 5.

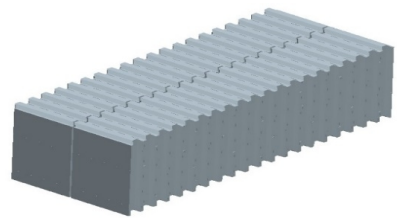

Fig. 4 block of foam sheet first step in cutting shape

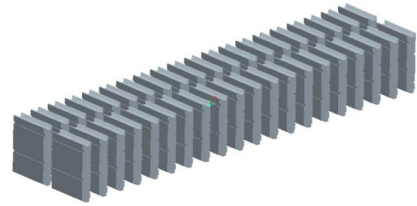

Fig. 5 The second step after cutting shape

The Selection of Ball Screw. Ball screw is by screw, steel ball, preloading, reverser, dust prevention device structure. It will work flow for forward spinning process changing for straight line process, this is actmix further extension and development of screw, its innovation significance lies in the change sliding for rolling operation. Because of the very small friction resistance, ball 
screw is widely used in all kinds of industrial equipment and precision instruments. Ball screw is the most commonly used on machine tools and precision machinery transmission components, its main function is to convert rotary motion to linear motion, or will be converted to repeated axial force, torque and combine the characteristics of high accuracy, reversibility and efficiency. The ball screw is shown as Fig. 6.

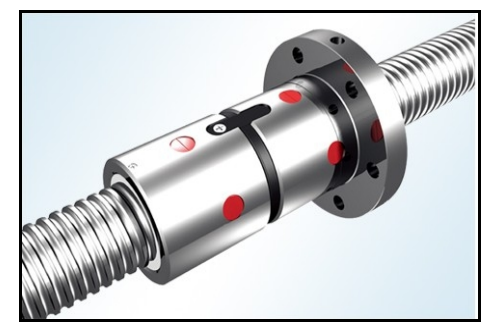

Fig. 6 Ball screw

Motor drive part. This equipment adopts 86 motor specifications in the following Table 1.

Table 186 Motor physical Specifications

\begin{tabular}{|c|c|}
\hline $\begin{array}{l}\text { Step from } \\
\text { the Angle of } \\
\text { precision }\end{array}$ & $0.06^{\circ}$ ( no-load \\
\hline $\begin{array}{l}\text { Temperatur } \\
\text { e rise }\end{array}$ & $80 \mathrm{~K}$ \\
\hline $\begin{array}{l}\text { environmen } \\
\text { tal conditions }\end{array}$ & $\begin{array}{l}\text { temperature : }-10 \sim+50^{\circ} \mathrm{C} \text {; humidity: } \\
85 \% \mathrm{MAX}\end{array}$ \\
\hline $\begin{array}{l}\text { Insulation } \\
\text { class }\end{array}$ & B \\
\hline $\begin{array}{l}\text { Insulation } \\
\text { resistance }\end{array}$ & $100 \mathrm{M} \Omega \mathrm{MIN} 500 \mathrm{VDC}$ \\
\hline $\begin{array}{l}\text { Withstand } \\
\text { voltage }\end{array}$ & 1000VAC $1 \mathrm{~min}$ \\
\hline $\begin{array}{l}\text { Radial } \\
\text { runout }\end{array}$ & $0.025 \mathrm{~mm} \operatorname{MAX}(\operatorname{load} 5 \mathrm{~N})$ \\
\hline $\begin{array}{l}\text { The axial } \\
\text { runout }\end{array}$ & $0.075 \mathrm{~mm}$ MAX( load 10N) \\
\hline
\end{tabular}
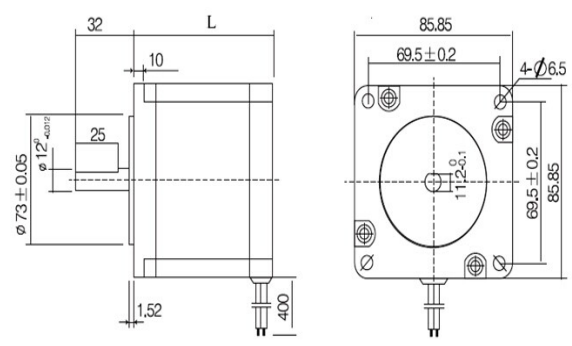

Fig. 7 Motor details

The actual prototype production. The front of the cutter design reference to the design of the electric spark cutting machine, vertical Longmen vertical cutting wire (assembly) fixed on the cross 
slide table, by two stepper motors control coupling, drive screw rotation fixed on both ends of the bearing. As a result, the vertical direction of the goal not only can realize linear cutting, but also can realize complex curve cutting. Cutting machine itself should have flexible cutting, solid and stable, the characteristics of the beautiful, so choose stainless steel as the main frame structure on the material. The mechanical transmission device in the scope of application can have the effect of good support and synchronous transmission, not changeful form, clipping, convenient and flexible, beautiful shape. Physical simulation prototype diagram as shown in figure 3.1, the actual cutting finished product figure as shown in Fig. 8.

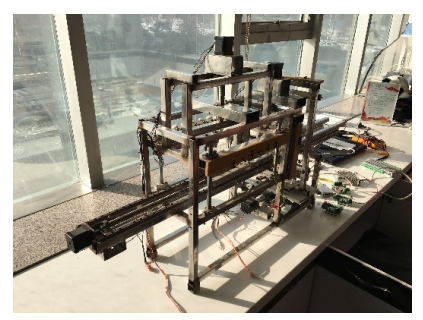

Fig. 8 simulation prototype physical figure

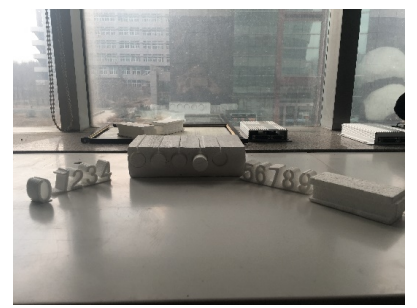

Fig. 9 actual cutting finished product figure

\section{Conclusion}

Socket type EPS plate cutting machine, cutting the modelling of the EPS board, implements the socket type foam plank cutting, CNC bulk forming mode from injection molding to cutting, injection molding method to reduce the production cost by about $67 \%$, compared to improve the efficiency of more than four times; Implements the dovetail groove, saw shaped groove, trapezoidal groove cutting various special-shaped trough; Implements the European-style building eaves line, the foot line, the Roman column form, such as cutting. In control of work, the realization of the cutting wire temperature, degree of tension and feed speed reasonable matching, finish temperature and feed speed closed-loop adjustment, realize three high three low, namely to achieve high accuracy, high efficiency, high security, low power consumption, low cost, low rejection rate for the purpose .

\section{Acknowledgements}

This work was financially supported by Changchun Science and Technology Bureau(13KG71), Jilin Education Department, and Jilin Science and Technology Department(20160623016TC).Jilin Agricultural University Science and Technology Innovation Fu nd Project: the Small Socket Type EPS Cutting Machine. 


\section{References}

[1] M.L. Zhou: Shanghai Building Material, Vol. 20(2008), No.7, p.04-15.

[2] S.Xiao: China Building Waterproofing, (2005), No.7, p.42-44.

[3] M. Han: Western China Science and technology, (2010), No.24, p.51-52.

[4] H.B. Xu: Journal of Jilin University, (2012), No.4

[5] Y.H. Zhang.2006. Economic Daily.

[6] S.Q. Liu: EP - EPS cushion packaging material preparation technology research .Beijing:

Beijing Institute of Graphic Communication, 2010.

[7]R.f.Hamamde,F.Zeineddine,B.Akle and A.Smailt,Modelangelo:A Subtractive 5-axis Robotic Arm for Rapid Prototyping.Robotic and Computer-Intergrated Manufacturing,(2005),NO.21,p.133-144.

[8] M.W. Yu, S.H. Wang, B.R. Qin, H.Cai: Mechanical design and manufacturing engineering, (2015), NO.1, p.33-36. 